\title{
A Review of Scientific Evidence for THC:CBD Oromucosal Spray (Nabiximols) in the Management of Chronic Pain
}

This article was published in the following Dove Press journal: Journal of Pain Research

\author{
Michael A Überall \\ Institute of Neurological Sciences, \\ Nürnberg, Germany
}

Correspondence: Michael A Überall Institute of Neurological Sciences, Nordostpark 5I, Nürnberg 904II, Germany

Email michael.ueberall@ifnap.de

\begin{abstract}
The $20 \%$ prevalence of chronic pain in the general population is a major health concern given the often profound associated impairment of daily activities, employment status, and health-related quality of life in sufferers. Resource utilization associated with chronic pain represents an enormous burden for healthcare systems. Although analgesia based on the World Health Organization's pain ladder continues to be the mainstay of chronic pain management, aside from chronic cancer pain or end-of-life care, prolonged use of non-steroidal anti-inflammatory drugs or opioids to manage chronic pain is rarely sustainable. As the endocannabinoid system is known to control pain at peripheral, spinal, and supraspinal levels, interest in medical use of cannabis is growing. A proprietary blend of cannabis plant extracts containing delta-9-tetrahydrocannabinol (THC) and cannabidiol (CBD) as the principal cannabinoids is formulated as an oromucosal spray (USAN name: nabiximols) and standardized to ensure quality, consistency and stability. This review examines evidence for THC:CBD oromucosal spray (nabiximols) in the management of chronic pain conditions. Cumulative evidence from clinical trials and an exploratory analysis of the German Pain e-Registry suggests that add-on THC:CBD oromucosal spray (nabiximols) may have a role in managing chronic neuropathic pain, although further precise clinical trials are required to draw definitive conclusions.
\end{abstract}

Keywords: THC:CBD oromucosal spray, chronic pain, neuropathic pain, nabiximols

\section{Introduction}

Chronic pain is defined as persistent or recurring pain lasting longer than 3 months that is characterized by persistent physical pain, disability, emotional disturbance, and social withdrawal. ${ }^{1}$ The eleventh International Classification of Diseases (ICD-11) divides chronic pain into seven categories: primary, cancer, post-traumatic and postsurgical, neuropathic, headache and orofacial, visceral, and musculoskeletal. ${ }^{2}$ The most common conditions associated with chronic pain are back pain, joint pain due to osteoarthrosis, osteoporosis or rheumatic diseases, and cancer. ${ }^{3-5}$ Neuropathic pain is defined as pain due to a primary lesion or dysfunction in the nervous system. ${ }^{6,7}$

Although estimates for chronic pain prevalence vary according to its definition, the population analyzed, and the method used to collect data, the burden is sizeable, affecting more than $20 \%$ of people globally irrespective of world region. ${ }^{8-14}$

By interfering with daily activities, employment status and the ability to work effectively, chronic pain can profoundly impair the general well-being of sufferers. Chronic pain is frequently accompanied by depression, anxiety and sleeping difficulties which combine 
to further reduce health-related quality of life (HR-QoL). The cumulative burden of chronic pain becomes more pronounced with increasing severity. ${ }^{8,15,16}$ Studies investigating the burden of chronic neuropathic pain report similar findings in terms of high rates of comorbid depression, anxiety, and sleeping difficulties/insomnia, negative impacts on employment status and ability to work, and impaired HR-QoL. ${ }^{17-20}$

Chronic pain has a substantial economic cost largely due to increased health resource utilization. In 2010 in the United States (US), total annual costs attributable to chronic pain were estimated to be USD \$560-635 billion. ${ }^{21}$ In Europe, the direct and indirect healthcare costs of chronic pain disorders are estimated to be $2-3 \%$ of GDP across member states, ${ }^{16}$ which amounted to about $€ 450$ billion in $2016 .^{22}$

\section{Management of Chronic Pain}

Optimal management of chronic pain involves a combination of medical and psychosocial approaches aimed at shifting the focus of treatment from pain relief towards increased function and well-being despite pain. ${ }^{1}$ In actual practice, however, pharmacological therapies continue to be the mainstay of general management of chronic pain. Analgesics for use in chronic pain include paracetamol, nonsteroidal anti-inflammatory drugs (NSAIDs) and opioids as per the WHO analgesic ladder, supplemented by adjuvant agents (eg muscle relaxants, anxiolytics, or hypnotics). ${ }^{23,24}$ With the possible exceptions of chronic cancer pain and end-of-life care, however, pharmacological analgesia is rarely a sustainable approach to chronic pain management due to safety limitations and abuse/misuse potential associated with prolonged use of these agents. ${ }^{1}$

A major contributing factor to the opioid epidemic in the US was increased opioid prescribing as part of a wider strategy to improve pain management, but ultimately leading to a dramatic increase in the number of prescription opioid overdose deaths. ${ }^{25}$ Epidemiological data suggest that opioid misuse is also a concern in Europe. ${ }^{26-28}$ In 2017, the six countries with the highest opioid consumption (reported as defined daily doses per million inhabitants per day) were, in order, the US, Germany, Canada, Austria, Belgium, and Switzerland. ${ }^{28}$

To control the opioid crisis, guidelines currently recommend against the use of opioids to manage chronic pain. In the US, the Centers for Disease Control (CDC) guidelines advocate non-pharmacological and non-opioid pharmacological therapies as the preferred choices to manage chronic pain. $^{25,29}$ The CDC and American Society of Interventional Pain Physicians guidelines recommend that opioid therapy be considered for chronic pain only if the benefits in terms of pain relief and improved function are likely to outweigh risks to the patient. ${ }^{25,29,30}$ The European Pain Federation's expert recommendations about safe and appropriate use of opioids in chronic pain management advise that opioid therapy be initiated only after failure of less potent analgesics and adjuvant therapies and/or rehabilitation to achieve and maintain adequate pain relief. ${ }^{31}$ In pain types with limited response to opioid medications (eg neuropathic pain), the European Federation of Neurological Societies guidelines recommend a diverse range of agents for first-, second- and third-line treatment (Table 1). ${ }^{32}$ These recommendations reflect the varying origins and difficult-to-control nature of chronic neuropathic pain, and also highlight the lack of effective new agents to manage neuropathic pain conditions.

\section{Cannabinoids in Chronic Pain Management}

\section{Mechanism of Action of Cannabinoids}

The discovery of the endocannabinoid system, and its role in pain control and habituation to stress, suggested that

Table I European Federation of Neurological Societies Recommended Treatment for Common Neuropathic Pain Conditions

\begin{tabular}{|l|l|l|}
\hline Condition & First Line & $\begin{array}{l}\text { Second or Third } \\
\text { Line }\end{array}$ \\
\hline $\begin{array}{l}\text { Diabetic } \\
\text { neuropathic pain }\end{array}$ & $\begin{array}{l}\text { Duloxetine } \\
\text { Gabapentin } \\
\text { Pregabalin } \\
\text { Tricyclic } \\
\text { antidepressants } \\
\text { Venlafaxine } \\
\text { extended release }\end{array}$ & $\begin{array}{l}\text { Opioids } \\
\text { Tramadol }^{\dagger}\end{array}$ \\
\hline Post-herpetic & $\begin{array}{l}\text { Gabapentin } \\
\text { Pregabalin } \\
\text { Tricyclic } \\
\text { antidepressants } \\
\text { Lidocaine plasters }\end{array}$ & $\begin{array}{l}\text { Capsaicin } \\
\text { Opioids }\end{array}$ \\
\hline $\begin{array}{l}\text { Classical trigeminal } \\
\text { neuralgia }\end{array}$ & $\begin{array}{l}\text { Carbamazepine } \\
\text { Oxcarbazepine }\end{array}$ & \begin{tabular}{l} 
Surgery \\
\hline Central pain
\end{tabular} \\
$\begin{array}{l}\text { Gabapentin } \\
\text { Pregabalin } \\
\text { Tricyclic } \\
\text { antidepressants }\end{array}$ & $\begin{array}{l}\text { Opioids } \\
\text { Tramadol (spinal cord } \\
\text { injury) }\end{array}$ \\
\hline
\end{tabular}

Notes: Adapted with permission from Attal N, Cruccu G, Baron R, et al. European Federation of Neurological Societies. EFNS guidelines on the pharmacological treatment of neuropathic pain: 2010 revision. Eur J Neurol. 2010; 17(9): I I 13-e88. ${ }^{32}{ }^{\dagger}$ Tramadol may be considered first line in patients with acute exacerbations of pain especially in combination with acetaminophen. ${ }^{\S}$ Lidocaine is recommended in elderly patients. 
cannabinoids may be useful to manage pain conditions. ${ }^{33,34}$ Delta-9-tetrahydrocannabinol (THC), a partial agonist of cannabinoid type $1\left(\mathrm{CB}_{1}\right)$ and type $2\left(\mathrm{CB}_{2}\right)$ receptors, mimics the effects of endogenous cannabinoids. ${ }^{35-38} \mathrm{CB}_{1}$ receptors, which mediate many of the psychoactive effects of cannabinoids, are commonly localized on preterminal axonal regions and axons in several brain regions, although they are also present in some peripheral tissues. $\mathrm{CB}_{2}$ receptors are found in a few neurons, but mainly in immune and hematopoietic cells. ${ }^{36,37,39,40}$ Cannabinoid receptors are members of the $\mathrm{G}$ protein-coupled, 7-transmembrane domain receptor superfamily. Endogenous ligands of these receptors, known as endocannabinoids, are the arachidonic acid derivatives $\mathrm{N}$-arachidonoylethanolamine (anandamide) and 2-arachidonoylglycerol. ${ }^{40,41}$ Endocannabin oids act as neuromodulators, ${ }^{42,43}$ and are important signaling molecules in neuronal and glial development. ${ }^{44}$

THC-mediated activation of presynaptic $\mathrm{CB}_{1}$ receptors inhibits neurotransmitter release in excitatory glutamatergic and inhibitory $\gamma$-aminobutyric acid (GABA) neurons in pathways including the hippocampus following disruption of synaptic function. ${ }^{45,46}$ Cannabidiol (CBD) has no agonistic effects on $\mathrm{CB}_{1}$ and $\mathrm{CB}_{2}$ receptors, ${ }^{35}$ although in experimental conditions (concentrations $<1 \mu \mathrm{M}$ ) it has shown noncompetitive negative allosteric modulation of $\mathrm{CB}_{1}$ receptors. ${ }^{47}$ The effects of $\mathrm{CBD}$ are likely due to modulation of multiple non-endocannabinoid signaling systems. ${ }^{36,48,49}$ At micromolar/sub-micromolar concentrations, CBD blocks equilibrative nucleoside transporters that mediate the transport of nucleosides, nucleobases and therapeutic analogs $;^{50}$ modulates the transient receptor potential of the melastatin type 8 ion channel which is the primary cold sensor in humans; ${ }^{51}$ and modulates the orphan G-protein-coupled receptor GPR55, a probable lysophosphatidylinositol receptor involved in multiple physiological and pathophysiological pathways. ${ }^{52}$ In addition, $\mathrm{CBD}$ enhances the activity of 5- $\mathrm{HT}_{1 \mathrm{a}}$ receptors which are key mediators of anxiety and depression-like behaviors; ${ }^{53}$ enhances the activity of $\alpha 1$ and $\alpha 3$ glycine receptors whose inhibitory actions contribute to control of excitability within the central nervous system; ${ }^{54}$ and modulates the activity of transient receptor potential ankyrin type 1 channels which play a critical role in cortical spreading depression and are a target for pain management. ${ }^{55} \mathrm{CBD}$ has bidirectional effects on intracellular calcium ions, and is a potent antioxidant. ${ }^{36,48,49}$

Activation of cannabinoid receptors by endogenous or extraneously administered cannabinoids has multiple analgesia-associated effects mediated by the peripheral and central nervous systems. ${ }^{40}$ These effects include inhibition of ascending nociceptive transmission, activation of the inhibitory descending pathway, and modification of the emotional component of pain. Activation of $\mathrm{CB}_{1}$ receptors localized in peripheral nociceptive terminals inhibits the activity of nociceptive neurons. At the spinal level, activation of $\mathrm{CB}_{1}$ receptors localized in dorsal root ganglia and in the spinal cord dorsal horn (in nociceptive and non-nociceptive sensitive terminals) inhibits neurotransmitter release and pain transmission. At the supraspinal level, activation of $\mathrm{CB}_{1}$ receptors localized mainly in the thalamus inhibits ascending nociceptive transmission and activates the descending inhibitory pathway by inhibition of GABA release. The emotional and cognitive effects of pain are modified by $\mathrm{CB}_{1}$ receptor activation acting in the limbic system and cortical areas of the brain. In addition, activation of peripheral $\mathrm{CB}_{2}$ receptors localized on immune cells and keratinocytes reduces the release of pronociceptive molecules. At the spinal cord level, $\mathrm{CB}_{2}$ receptor activation modulates immune responses, leading to inhibition of neuronal sensitization during chronic pain (Figure 1).

In preclinical rodent models, activation of cannabinoid receptors reduced neuropathic and chronic inflammatory pain. $^{35,40,48}$ Recently, in a well-established nerve injury model of neuropathic pain, treatment with CBD for 7 days normalized impaired serotonergic (5-HT) neurotransmission, reduced mechanical allodynia and decreased anxiety-like behavior. $^{56}$ The findings are important since they show that the effects of CBD relate not only to a reduction in pain intensity and modification of pain quality, but especially to a change in anxiety-related behavior.

\section{Cannabinoids for Pain Management}

Use of herbal cannabis (smoked, vaporized, orally ingested), at present at least, is not suitable to manage pain or other medical conditions. Aside from practical issues such as restricted availability as regulated by national or regional health authorities, risks of herbal cannabis include variability in cannabinoid type and potency, potential for misuse/dependency, and possible future mental health-related consequences in young people. ${ }^{57}$

Numerous studies have investigated cannabis and its derivatives to treat myriad conditions, including chronic pain. As a discussion of the full range of cannabis and cannabis-based products is beyond the scope of this review, interested readers are directed to recent comprehensive reviews on the subject. $^{58,59}$ Plant-derived (ie phytocannabinoids) and synthetic cannabinoids currently available for medicinal use are described briefly before the focus is turned specifically to THC:CBD oromucosal spray (nabiximols) for management of chronic pain conditions. 


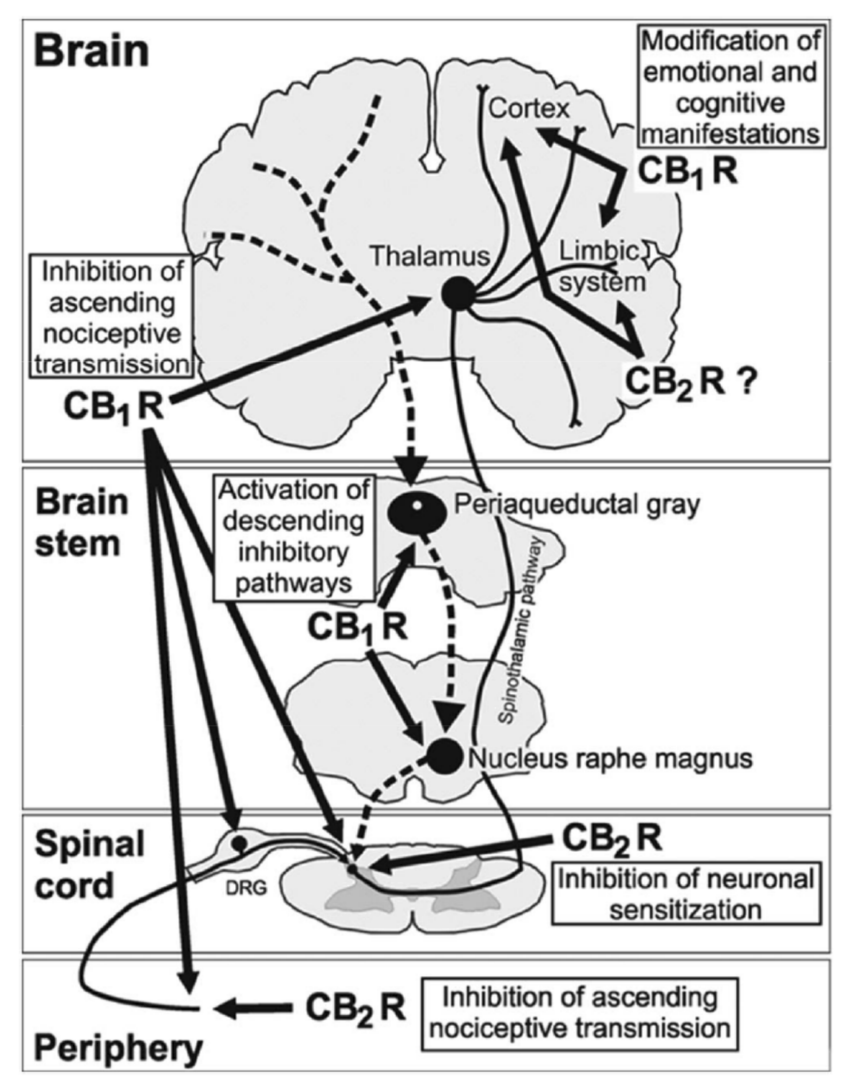

Figure I Role of the endocannabinoid system in the control of pain at peripheral, spinal, and supraspinal levels. Cannabinoid receptor activity inhibits the ascending nociceptive transmission, activates the inhibitory descending pathway, and modifies the emotional component of pain. $C B_{1} R$, Cannabinoid type I receptor; $C_{2} R$, Cannabinoid type I receptor. Reproduced with permission from Maldonado $R$, Baños JE, Cabañero $D$. The endocannabinoid system and neuropathic pain. Pain. 2016;157(Suppl I):S23-S32. Available from: https://insights.ovid.com/article/00006396-20160200I-00005. ${ }^{40}$

Sativex ${ }^{\circledR}$ (USAN name: nabiximols) oromucosal spray is a phytocannabinoid extract containing THC and CBD (1:1 ratio) as its principal components. The methodology for producing THC:CBD spray (nabiximols) is well described. ${ }^{60}$ The medicine is produced from two chemovars of the $C$. sativa plant with each clone producing a high level of $\mathrm{THC}$ or $\mathrm{CBD}^{61}$ and is standardized to ensure quality, consistency and stability. ${ }^{60}$ THC and CBD are thought to interact synergistically with other trace cannabinoids to provide activity greater than that of the individual components. ${ }^{62} \mathrm{CBD}$ has a dual mechanism; it potentiates the depressant effects of THC while inhibiting its excitatory and emotional effects. $^{62}$ The oromucosal route of administration avoids the high THC plasma levels that occur after inhaling herbal cannabis and are responsible for the psychoactivity. ${ }^{63-65}$ Other negative associations with smoking cannabis such as an increased risk of lung cancer ${ }^{66}$ are also avoided by oromucosal delivery. THC:CBD oromucosal spray (nabiximols) is approved in several countries as an add-on treatment for moderate to severe resistant multiple sclerosis (MS) spasticity. ${ }^{38}$
Other phytocannabinoids containing multiple different cannabinoids (eg Bedrocan ${ }^{\circledR}$ ) have yet to undergo clinical trial development or receive approval for a first official indication. A plant-derived medicine containing single purified CBD (cannabidiol oral solution, Epidiolex ${ }^{\circledR}$ ) was recently approved by the US Food and Drug Administration and European Medicines Agency for treatment of the rare epileptic syndromes, LennoxGastaut and Dravet. ${ }^{67,68}$ Dronabinol (Marinol ${ }^{\circledR}$, Syndros $^{\circledR}$ ) is a synthetic THC indicated for treatment of anorexia associated with weight loss in patients with AIDS, and treatment of severe refractory nausea and vomiting associated with cancer chemotherapy. ${ }^{69,70}$ Nabilone $\left(\right.$ Cesamet $^{\circledR}$, Canemes $^{\circledR}$ ) is a THC analog indicated for treatment of severe refractory nausea and vomiting associated with cancer chemotherapy. ${ }^{71}$

The European Pain Federation has published a position paper about the appropriate use of cannabis-based medicines and medical cannabis for chronic pain management. Key points are that: 1) current evidence is insufficient to state whether cannabis-based medicines and medical cannabis differ in their efficacy, tolerability and safety; 2) cannabis-based medicines can be considered as third-line therapy for chronic neuropathic pain; 3) THC:CBD oromucosal spray (nabiximols) can be considered as part of an add-on individual therapeutic trial for individuals with cancer pain who have inadequate pain relief from opioids or other established analgesics, ${ }^{72}$ although evidence for this latter recommendation is limited.

\section{Search Strategy and Study Identification}

To identify clinical trials of THC:CBD oromucosal spray (nabiximols) in chronic pain, searches were conducted of PubMed, Cochrane Library, and ClinicalTrials.gov using the search terms: Sativex, delta-9-tetrahydrocannabinol, cannabidiol, THC:CBD, nabiximols, medical cannabis, chronic pain, pain, and neuropathic pain. There were no language restrictions. In the case of PubMed searches, the "clinical trial" filter was applied. Reference lists of retrieved papers were hand-searched for additional clinical studies. Other references are known to the author or are part of his collection.

\section{THC:CBD Oromucosal Spray (Nabiximols) in Pain Management} Treatment of Multiple Sclerosis Spasticity In an early randomized controlled trial (RCT) in patients with MS, THC:CBD oromucosal spray (nabiximols) for 6 weeks significantly improved MS spasticity (muscle rigidity with [often painful] spasms) versus placebo as 
assessed by mean Visual Analogue Scale (VAS) scores. ${ }^{73}$ In three pivotal RCTs of patients with refractory MS spasticity (treatment duration 6 to 14 weeks), THC: CBD oromucosal spray (nabiximols) significantly improved mean spasticity $0-10$ numerical rating scale (NRS) scores and mean pain 0-10 NRS scores compared with placebo. ${ }^{74-76}$ The post-approval SAVANT (Sativex as Add-on therapy vs further optimized first-line ANTispastics) trial showed that 12 weeks' add-on treatment with THC:CBD oromucosal spray (nabiximols) produced clinically relevant $(\geq 30 \%$ NRS reduction from baseline) improvement of resistant MS spasticity and associated pain than that achieved by adjusting underlying first-line antispasticity medication alone. ${ }^{77}$

During clinical development of THC:CBD oromucosal spray (nabiximols) for MS spasticity, the most common treatment-related adverse events were mild to moderate transient episodes of dizziness, fatigue or somnolence. ${ }^{38,78}$ Less commonly, mucosal irritation was reported. ${ }^{38}$ To date, THC:CBD oromucosal spray (nabiximols) has not been associated with drug tolerance or a withdrawal syndrome ${ }^{79}$ and there has been no evidence of drug misuse or abuse. ${ }^{38}$ The estimated total post-marketing exposure of THC:CBD spray (nabiximols) at the end of 2018 was more than 120,000 patient-years. ${ }^{80}$

European consensus guidelines on pharmacological management of MS spasticity recommend adding THC:CBD oromucosal spray (nabiximols) to current therapy in patients with moderate to severe spasticity who have a suboptimal response or poor tolerance to first-line oral treatments. ${ }^{81}$

\section{Treatment of Chronic Cancer-Related Pain}

Chronic cancer pain is classified pathophysiologically as nociceptive, neuropathic or mixed nociceptive/neuropathic ${ }^{82}$ in alignment with the general classification of chronic pain.

The results of placebo-controlled clinical trials of THC: $\mathrm{CBD}$ oromucosal spray (nabiximols) in chronic cancer-related pain have been variable. Efficacy was demonstrated in two studies. In a clinical trial involving patients $(\mathrm{n}=177)$ with intractable cancer-related pain, mean pain 0-10 NRS scores were significantly improved after 2 weeks' treatment with active medication compared with placebo (change from baseline: -1.37 vs $-0.69 ; p=0.014)$. About twice as many patients treated with THC:CBD (nabiximols) than placebo (43\% vs $21 \%$ ) achieved a clinically meaningful $\geq 30 \%$ reduction from baseline in pain 0-10 NRS scores. Treatment-related adverse events were mostly mild or moderate and similar to the known safety profile of THC:CBD spray (nabiximols) in MS spasticity, namely somnolence, dizziness and nausea. ${ }^{83}$ A subsequent open-label extension study involving 39 patients who had received THC:CBD spray in the parent study showed that extended use (median 25 days, range 2-579 days) was generally well tolerated. Patients did not seek to increase their dose of THC:CBD spray (nabiximols) or other pain-relieving medication during extended use. The mean dose during the last 7 days of dosing ( 5.4 sprays/day) was lower than the mean dose (8.75 sprays/day) in the first weeks of the parent study. ${ }^{84}$ In another placebo-controlled trial of THC:CBD oromucosal spray (nabiximols) in patients with opioid-refractory cancer pain $(n=360)$, the primary outcome $(30 \%$ responder rate $)$ after 5 weeks' treatment was not met $(\mathrm{p}=0.59)$, although patient-reported analgesia rates were significantly higher with active medication than placebo $(\mathrm{p}=0.035)$. A dose-grading analysis indicated that analgesia rates were significantly higher with low-dose ( $1-4$ sprays/day; $p=0.008)$ and medium-dose (6-10 sprays/day; $p=0.039)$ THC:CBD spray (nabiximols) than placebo. Adverse events compared unfavorably with placebo only in the high-dose group. ${ }^{85}$

In a third large placebo-controlled clinical trial in advanced cancer patients with chronic uncontrolled pain $(\mathrm{n}=397)$, the change from baseline in the mean pain 0-10 NRS score at the end of treatment (2-week titration, 3-week treatment) favored THC:CBD oromucosal spray (nabiximols) but without reaching statistical significance (10.7\% vs $4.5 \% ; p=0.0854)$. The benefits of THC:CBD spray (nabiximols) on multiple secondary endpoints were observed mainly in US patients, possibly due to lower baseline opioid doses compared with European patients or due to differences in the distribution of cancer pain types between US and Europe patient populations. The safety profile of THC:CBD spray (nabiximols) was consistent with that reported in earlier studies. ${ }^{86}$

\section{Treatment of Chronic Neuropathic Pain}

Randomized clinical trials of THC:CBD oromucosal spray (nabiximols) for the treatment of chronic neuropathic pain conditions are summarized in Table $2 .{ }^{87-90,92-98}$

THC:CBD oromucosal spray (nabiximols) has shown mainly positive results in studies of patients with MSassociated neuropathic pain (Table 2) ${ }^{87-90}$

A placebo-controlled RCT of patients with central neuropathic pain due to MS reported a near 2-fold higher mean change from baseline on the $0-10$ pain NRS ( -2.7 vs -1.4 ; $\mathrm{p}=0.005)$ during 4 weeks' treatment with THC:CBD oromucosal spray (nabiximols) or placebo as adjunctive 
Table 2 Randomized Clinical Trials and Extension Studies of THC:CBD Oromucosal Spray (Nabiximols) in Neuropathic Pain

\begin{tabular}{|c|c|c|c|c|c|c|}
\hline Reference & $\begin{array}{l}\text { Neuropathic } \\
\text { Pain Study }\end{array}$ & $\begin{array}{l}\text { Randomized/Entered } \\
\text { Extension Study, n }\end{array}$ & $\begin{array}{l}\text { Completed, } \\
\text { n }\end{array}$ & $\begin{array}{l}\text { Treatment } \\
\text { Duration }\end{array}$ & $\begin{array}{l}\text { Change in Pain 0-10 NRS for } \\
\text { THC:CBD Oromucosal Spray } \\
\text { (Nabiximols) vs Placebo }\end{array}$ & $p$-value \\
\hline [87] & Multiple sclerosis & 66 & 64 & 4 weeks & -2.7 vs $-1.4(\Delta$ । .3$)$ & 0.005 \\
\hline [88] & $\begin{array}{l}\text { Multiple sclerosis } \\
\text { (open-label } \\
\text { extension of }\end{array}$ & 63 & $\begin{array}{l}34 \text { ( } 1 \text { year }) \\
28 \text { ( } 2 \text { years })\end{array}$ & 2 years & $-2.9^{\dagger}$ & N/A \\
\hline [89] & Multiple sclerosis & 339 & 297 & 14 weeks & -1.93 vs $-1.76(\Delta 0.17)$ & 0.47 \\
\hline [90] & $\begin{array}{l}\text { Multiple sclerosis or } \\
\text { other defects of } \\
\text { neurological } \\
\text { function }\end{array}$ & 70 & 63 & 3 weeks & -1.3 vs $-0.9(\Delta 0.4)^{\S}$ & 0.33 \\
\hline [92] & Spinal cord injury & 116 & 106 & 3 weeks & -0.74 vs $-0.69(\Delta 0.05)$ & 0.71 \\
\hline [93] & $\begin{array}{l}\text { Brachial plexus } \\
\text { avulsion }\end{array}$ & 48 & 45 & 2 weeks & $\Delta-0.58$ vs placebo ${ }^{\S}$ & 0.005 \\
\hline [94] & Allodynia & 125 & 105 & 5 weeks & -1.48 vs $-0.52(\Delta 0.97)$ & 0.004 \\
\hline [95] & Allodynia & 246 & 173 & I4 weeks & $\Delta-0.34$ vs placebo & 0.139 \\
\hline [96] & Diabetes & 297 & 230 & 14 weeks & -1.67 vs $-1.55(\Delta 0.12)$ & 0.63 \\
\hline [97] & $\begin{array}{l}\text { Allodynia or } \\
\text { diabetes (open-label } \\
\text { extension of }{ }^{95,96}\end{array}$ & $\begin{array}{l}380 \text { (I } 76 \text { allodynia, } 204 \\
\text { diabetes) }\end{array}$ & $\begin{array}{l}234 \text { (100 } \\
\text { allodynia, } 134 \\
\text { diabetes) }\end{array}$ & 38 weeks & -2.7 vs baseline $e^{\ddagger}$ & N/A \\
\hline [98] & $\begin{array}{l}\text { Chemotherapy- } \\
\text { induced }\end{array}$ & 18 & 16 & 6 weeks & $-\mathrm{I} .25$ vs $-0.44(\Delta 0.8 \mathrm{I})$ & 0.29 \\
\hline
\end{tabular}

Notes: ${ }^{\dagger}$ Mean pain 0-10 NRS score in patients completing 2 years' follow-up; ${ }^{\S} 0-10$ Box Scale score; ${ }^{\ddagger}$ Pain 0 - 10 NRS score decreased over time from a mean of 6.9 points (baseline in the parent studies) to a mean of 5.5 points (end of parent studies), to a mean of 4.2 points (end of open-label treatment) in remaining patients.

Abbreviation: NRS, numerical rating scale.

analgesia. More patients treated with THC:CBD oromucosal spray (nabiximols) than placebo reported dizziness, dry mouth, and somnolence. ${ }^{87}$ In a subsequent open-label extension study involving 63 of the 66 original participants, 28 patients (44\%) who completed 2 years' treatment with active medication recorded a mean pain 0-10 NRS score of 2.9 , although this evidence is acknowledged to be of lower quality than a RCT. Most patients (92\%) experienced one or more adverse events during long-term treatment, mainly dizziness and nausea, which were typically mild to moderate in intensity. There was no evidence of tolerance during up to 2 years' treatment. ${ }^{88}$

A larger placebo-controlled trial of add-on THC:CBD oromucosal spray (nabiximols) conducted in 339 patients with refractory central neuropathic pain due to MS failed to meet the primary endpoint due to a high placebo response. After 14 weeks' treatment, the proportion of patients with $\geq 30 \%$ NRS improvement was $50 \%$ and $45 \%$ in the THC:
CBD spray (nabiximols) and placebo groups, respectively $(p=0.234)$. Likewise, the change from baseline in pain 0-10 NRS scores did not differ significantly between groups ( -1.93 vs $-1.76 ; p=0.47)$. Among 58 patients who entered the 4 -week randomized withdrawal phase, the primary endpoint of time to treatment failure significantly favored THC:CBD spray (nabiximols), with $24 \%$ of patients failing treatment compared with $57 \%$ of patients treated with placebo $(\mathrm{p}=0.04)$. THC: CBD spray was generally well tolerated, with most adverse events judged as mild to moderate in severity. ${ }^{89}$

A RCT available at ClinicalTrials.gov which investigated THC:CBD oromucosal spray (nabiximols) for relief of chronic refractory neuropathic pain due to MS or other defects of neurological function found a numerical but not statistically significant advantage in favor of active medication versus placebo for the change from baseline in the mean pain box scale-11 score $(-1.3 \mathrm{vs}-0.9 ; \mathrm{p}=0.33)$ after 3 weeks' treatment (ClinicalTrials.gov identifier NCT01606176). ${ }^{90}$ 
Lastly, a small independent investigator-initiated nonrandomized study of $10 \mathrm{MS}$ patients with neuropathic pain showed that 4 weeks' treatment with THC:CBD oromucosal spray (nabiximols) significantly reduced the pain rating from baseline (assessed by VAS; $p=0.001$ ) and improved quality of life measures. Interestingly, the clinical effects observed with THC:CBD spray (nabiximols) were paralleled by an increase in fronto-central $\gamma$-band oscillation and pain-motor integration strength. ${ }^{91}$

The results of studies of THC:CBD spray (nabiximols) in patients with neuropathic pain of origins other than MS are mixed (Table 2). ${ }^{92-98}$

A RCT registered at ClinicalTrials.gov which compared THC:CBD spray (nabiximols) and placebo for relief of intractable neuropathic pain associated with spinal cord injury found no difference between treatments for change from baseline in pain $0-10$ NRS scores $(-0.74$ vs -0.69 ; $\mathrm{p}=0.71$ ) after 3 weeks' treatment (ClinicalTrials.gov identifier NCT01606202). ${ }^{92}$

In a study of central neuropathic pain due to brachial plexus avulsion, the difference in the mean pain severity score during the last 7 days of treatment with THC:CBD oromucosal spray (nabiximols) was statistically significant $(\mathrm{p}=0.005)$ compared with placebo, although failed to satisfy the a priori assumed level for clinical significance. ${ }^{93}$

In 125 patients with neuropathic pain of peripheral origin (eg diabetic neuropathy, post-herpetic neuralgia) characterized by allodynia, 4 weeks' double-blind treatment with THC:CBD oromucosal spray (nabiximols) was associated with a significant reduction in the mean pain 0-10 NRS score compared with placebo $(-1.48$ vs $-0.52 ; p=0.004)$. Significant improvements with THC:CBD spray (nabiximols) were observed in other endpoints including the Neuropathic Pain Scale composite score $(p=0.007)$, dynamic allodynia $(p=0.042)$, punctate allodynia $(p=0.021)$, Pain Disability Index $(p=0.003)$ and Patient's Global Impression of Change $(p<0.001)$. Adverse events reported by patients on active medication were mainly sedative or gastrointestinal. ${ }^{94}$ In a subsequent larger trial of THC:CBD spray (nabiximols) for peripheral neuropathic pain associated with allodynia $(n=303)$, the proportion of treatmentresponsive patients ( $\geq 30 \%$ NRS improvement from baseline) after 14 weeks' double-blind treatment was significantly higher with THC:CBD spray (nabiximols) than placebo $(p=0.034)$, but there was no significant difference between treatment groups for change from baseline in the mean pain 0-10 NRS score $(p=0.116)$. The most common treatment-related events with THC:CBD spray (nabiximols) were dizziness, nausea, fatigue and dysgeusia. ${ }^{95}$ Likewise, in an aligned ClinicalTrials. gov registered study of THC:CBD spray (nabiximols) in patients with peripheral neuropathic pain associated with diabetes $(n=297)$, the change from baseline in the mean pain 0-10 NRS score after 14 weeks' treatment was not significantly different compared with placebo $(-1.67$ vs $-1.55 ; \mathrm{p}=0.63)$ (ClinicalTrials.gov identifier NCT00710424) ${ }^{96}$ Patients who completed either of these two studies (allodynia, $\mathrm{n}=176$; diabetes, $n=204$ ) were entered into an open-label extension study to receive active medication for a further 38 weeks in addition to their current analgesic therapy. Among 234 patients ( $62 \%$ of the initial sample) who completed the extension phase, the mean pain 0-10 NRS score showed a decrease from 6.9 points at baseline in the parent studies to 4.2 points at the end of open-label follow-up. THC:CBD (nabiximols) spray was well tolerated during follow-on treatment with no evidence of development of tolerance. ${ }^{97}$

A small pilot trial with a randomized crossover design in patients with chemotherapy-induced neuropathic pain $(n=16)$ showed no statistically significant effect from treatment with THC:CBD oromucosal spray (nabiximols) compared with placebo for change from baseline in the mean pain 0-10 NRS score, although a responder analysis identified a small number of responders who may derive a clinically meaningful benefit from treatment. ${ }^{98}$

A placebo-controlled randomized trial of THC:CBD oromucosal spray (nabiximols) in patients with rheumatoid arthritis $(\mathrm{n}=58)$, a disease which causes both nociceptive and neuropathic pain, ${ }^{99}$ reported improvement after 5 weeks' treatment in the primary endpoint of morning pain on movement $(p=0.044)$, and in the secondary endpoints of morning pain at rest $(p=0.018)$ and "pain at present" component of the ShortForm McGill Pain Questionnaire $(\mathrm{p}=0.016){ }^{100}$ Adverse effects were mainly mild or moderate.

\section{Real-World Data for THC:CBD Oromucosal Spray (Nabiximols) in Chronic Pain}

A retrospective analysis of anonymized data collected in a large German Pain e-Registry has provided insight into the real-world management of severe chronic pain with THC: CBD oromucosal spray (nabiximols). ${ }^{101}$ Among 30,228 patients prospectively registered in the German Pain e-Registry within 2017, 800 (2.6\%) had received THC:CBD oromucosal spray (nabiximols) as an add-on therapy for pain relief. Prescribing of THC:CBD spray followed a change to German regulations permitting the use of cannabinoid preparations independently of their labels or even in the absence of 
a label in patients with resistant chronic pain conditions who fail previous management options. The main underlying chronic pain conditions in these patients were lower back pain (234 patients; 29.3\%), failed back surgery syndrome $(\mathrm{n}=148 ; 18.5 \%)$ and shoulder/neck pain $(\mathrm{n}=91 ; 11.4 \%)$. Pain phenotype (nociceptive, mixed, neuropathic) was evaluated using the painDETECT questionnaire (PDQ7). ${ }^{102,103}$ Most patients were taking analgesic opioids (86.5\% strong, $16.1 \%$ mild) at baseline.

Pain intensity measured on a $0-100$ VAS (from $0=$ no pain; to $100=$ worst pain conceivable) improved by at least $50 \%$ in $67.5 \%$ of patients after 12 weeks' treatment with THC:CBD oromucosal spray (nabiximols). Aggregated nine-factor symptom relief (ASR-9), a composite score that summarizes the outputs of nine pain evolution efficacy endpoints measured using validated instruments, was increased by $39 \%$ from baseline. Overall, $15.4 \%$ of patients $(n=123)$ showed at least $50 \%$ improvement in all nine factors, and $56.0 \%$ of patients $(\mathrm{n}=488)$ showed at least $50 \%$ improvement in $\geq$ five ASR-9 factors. Other symptoms with relief rates $\geq 50 \%$ were stress (78.8\%), depression (66.5\%), anxiety (57.6\%) and overall well-being $(61.3 \%$ ) (Figure 2 ). Outcomes in terms of $\geq 50 \%$ improvement in pain intensity rates and mean ASR-9 symptom relief/improvement scores were significantly greater in the neuropathic pain subgroup ( $94.8 \%$ and $54.9 \%$, respectively; $\mathrm{n}=497)$ versus the mixed pain $(24.9 \%$ and $18.2 \% ; \mathrm{n}=249)$ or nociceptive pain $(13.6 \%$ and $11.9 \% ; n=54)$ subgroups $(\mathrm{p}<$ 0.001 for all comparisons). Use of concomitant opioids, both as acute (rescue) or continuous pain treatment, was reduced. During the first 12 weeks of use of THC:CBD oromucosal spray (nabiximols), $18.1 \%$ of patients discontinued treatment due to inadequate efficacy $(14.1 \%, \mathrm{n}=113)$ or treatmentemergent adverse events (TEAEs) $(4 \%, \mathrm{n}=32)$. In all, 206 TEAEs were reported by 159 patients (19.9\%), most commonly increased appetite $(6.3 \%)$ or dysgeusia $(2.9 \%)$ of mild intensity. This safety profile differs from that observed in other large-scale observational studies of THC:CBD oromucosal spray (nabiximols) in patients with MS spasticity in which the most common adverse events (at mean doses of 6-7 sprays/day) were dizziness, fatigue and drowsiness. ${ }^{104,105}$

\section{Conclusions}

Chronic pain is a common and frequently debilitating condition that carries a large individual and societal

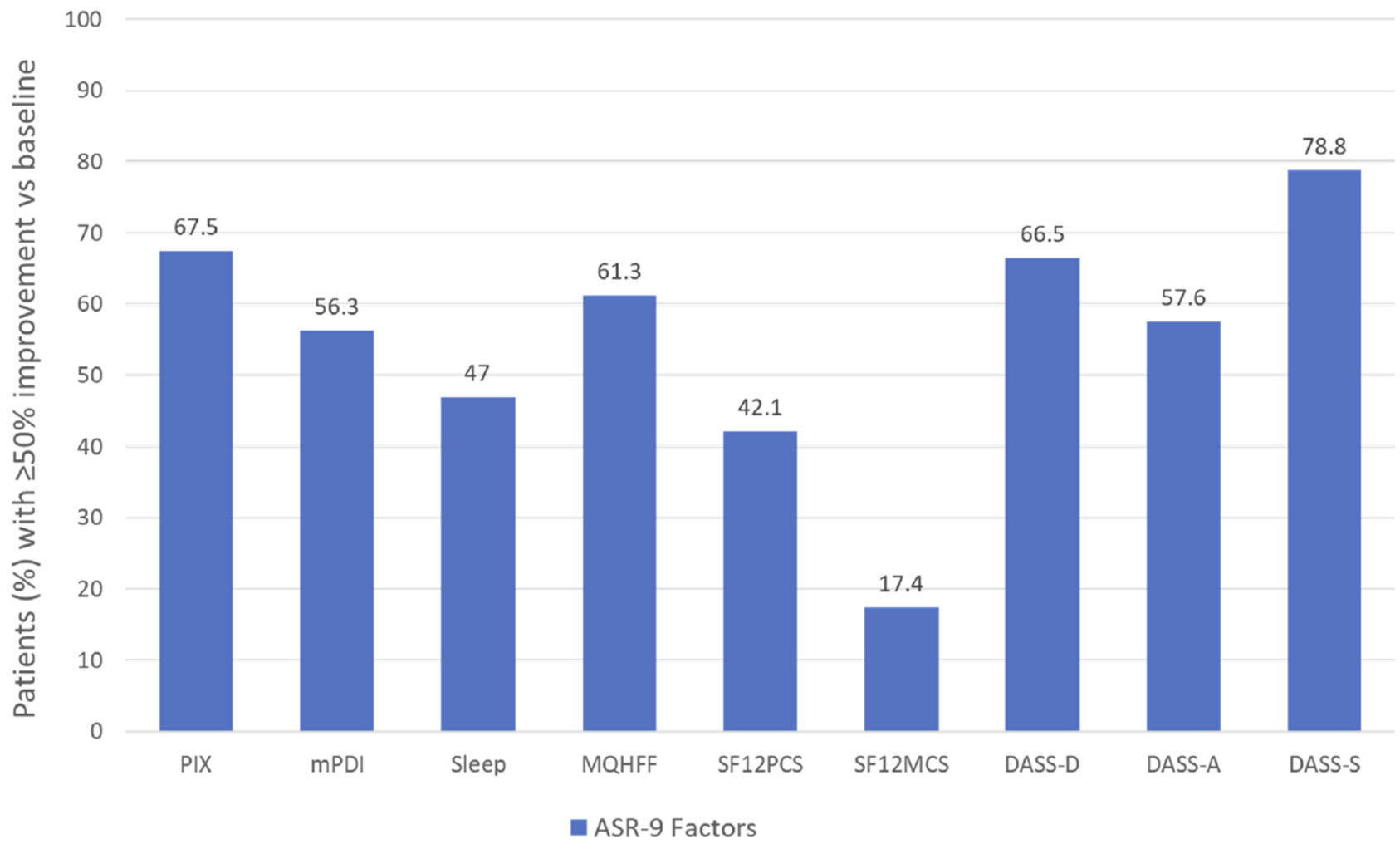

Figure 2 Proportion of patients with chronic pain (neuropathic 62.1\%; mixed 31.1\%; nociceptive 6.8\%) reporting $\geq 50 \%$ improvement from baseline in Aggregated 9-Factor Symptom Relief (ASR-9) scores after 12 weeks' treatment with THC:CBD oromucosal spray (nabiximols). Data from Ueberall et al (2019). ${ }^{101}$

Abbreviations: PIX, pain intensity index; mPDI, modified pain disability index; MQHFF, Marburg Questionnaire on Habitual Health Findings; SFI2PCS, Short Form I2-item Health Survey physical component score; SFI2MCS, Short Form 12-item Health Survey mental component score; DASS, Depression, Anxiety, Stress Scale. 
burden. Numerous etiological factors contribute to its development. Discovery of the endocannabinoid system and its role in pain control and habituation to stress suggested that cannabinoids may be useful to manage pain conditions. Activation of cannabinoid receptors has multiple analgesia-associated effects mediated by the peripheral and central nervous systems.

THC:CBD oromucosal spray (nabiximols), a cannabis-derived medicine approved for symptomatic relief of MS-related spasticity, has also been investigated as an add-on treatment for pain. Results of placebocontrolled clinical trials of THC:CBD oromucosal spray (nabiximols) in chronic cancer-related pain were equivocal. The analgesic efficacy of THC:CBD oromucosal spray (nabiximols) was more apparent in placebocontrolled clinical trials of chronic neuropathic pain, particularly MS-associated neuropathic pain, with some patients maintaining long-term (up to 2 years) benefit. A German Pain e-Registry analysis of patients with severe chronic pain treated in daily practice with THC: CBD oromucosal spray (nabiximols) showed best results in the neuropathic pain subgroup versus nociceptive or mixed pain subgroups. Across all reviewed studies in patients with chronic cancer-related or nonmalignant pain, no new safety concerns were identified with THC: CBD oromucosal spray (nabiximols) and there was no evidence of tolerance during extended use.

Anxiety and stress are recognized as major drivers for the development and maintenance of chronic pain. Looking ahead, if the ability of CBD to improve anxiety-related behavior in an animal model of neuropathic pain is corroborated in clinical studies, this may offer patients new perspectives for coping with chronic pain. Interestingly, these preclinical findings correlate with observations from the German Pain Practice e-Registry analysis which indicated that, beyond pain phenomenology, the presence of anxiety and stress are important predictors of response to treatment. Both symptoms improved significantly during treatment with THC:CBD oromucosal spray (nabiximols). This is an intriguing avenue for future research.

The main limitations of studies reviewed herein are the short duration (for a chronic condition), heterogenous patient populations and lack of active comparators. Although the data set for THC:CBD oromucosal spray (nabiximols) in chronic pain includes two extension studies, only limited numbers of patients received treatment long term.
To conclude, as improvement rates appeared to be lower in patients with pain types other than chronic neuropathic pain, proper diagnosis is key towards identifying patients most likely to benefit from THC:CBD oromucosal spray (nabiximols) as an adjunct to other treatment.

\section{Acknowledgments}

Writing assistance for this article was provided by Rob Furlong and Kerry Dechant on behalf of Content Ed Net (Madrid, Spain) with funding from Almirall S.A. (Barcelona, Spain).

\section{Disclosure}

Michael A Überall has received direct and/or indirect financial support in form of research grants, honorarium for consultancy, scientific advice, and/or lecture activities from Almirall, Aristo Pharma, Berlin Chemie, Bionorica, Esanum, Glaxo Smith Kline, Grünenthal, Hapa Medical, Hexal, KyowaKirin, Lilly, Menarini, Mucos, Mundipharma, Novartis, Pfizer, Pharm Allergan, Servier, SGP Pharma, Shionogi, Teva, and Tilray. The author reports no other conflicts of interest in this work.

\section{References}

1. Hylands-White N, Duarte RV, Raphael JH. An overview of treatment approaches for chronic pain management. Rheumatol Int. 2017;37:29-42. doi:10.1007/s00296-016-3481-8

2. Treede RD, Rief W, Barke A, et al. A classification of chronic pain for ICD-11. Pain. 2015;156:1003-1007. doi:10.1097/j.pain.0000000000000160

3. Siebenhuener K, Eschmann E, Kienast A, et al. Chronic pain: how challenging are DDIs in the analgesic treatment of inpatients with multiple chronic conditions? PLoS One. 2017;12:e168987. doi:10.1371/journal.pone. 0168987

4. Müller-Schwefe GH. European survey of chronic pain patients: results for Germany. Curr Med Res Opin. 2011;27:2099-2106. doi:10.1185/03007995.2011.621935

5. Langley PC, Ruiz-Iban MA, Molina JT, De Andres J, Castellón JR. The prevalence, correlates and treatment of pain in Spain. $J$ Med Econ. 2011;14:367-380. doi:10.3111/ 13696998.2011.583303

6. Treede RD, Jensen TS, Campbell JN, et al. Neuropathic pain: redefinition and a grading system for clinical and research purposes. Neurology. 2008;70:1630-1635. doi:10.1212/01. wn1.0000282763.29778.59

7. Colloca L, Ludman T, Bouhassira D, et al. Neuropathic pain. Nat Rev Dis Primers. 2017;3:17002. doi:10.1038/nrdp.2017.2

8. Breivik H, Collett B, Ventafridda V, Cohen R, Gallacher D. Survey of chronic pain in Europe: prevalence, impact on daily life, and treatment. Eur $J$ Pain. 2006;10:287-333. doi:10.1016/j.ejpain.2005.06.009

9. Gureje O, Von Korff M, Simon GE, Gater R. Persistent pain and well-being. A World Health Organization study in primary care. JAMA. 1998;280:147-151. doi:10.1001/jama.280.2.147

10. Bouhassira D, Lantéri-Minet M, Attal N, Laurent B, Touboul C. Prevalence of chronic pain with neuropathic characteristics in the general population. Pain. 2008;136:380-387. doi:10.1016/j. pain.2007.08.013 
11. Torrance N, Smith BH, Bennett MI, Lee AJ. The epidemiology of chronic pain of predominantly neuropathic origin. Results from a general population survey. $J$ Pain. 2006;7:281-289. doi:10.1016/j.jpain.2005.11.008

12. Fayaz A, Croft P, Langford RM, Donaldson LJ, Jones GT. Prevalence of chronic pain in the UK: a systematic review and meta-analysis of population studies. BMJ Open. 2016;6:e10364. doi:10.1136/bmjopen-2015-010364

13. Fatoye F, Gebrye T, Odeyemi I. Real-world incidence and prevalence of low back pain using routinely collected data. Rheumatol Int. 2019;39(4):619-626. doi:10.1007/s00296-019-04273-0

14. Toth C, Lander J, Wiebe $S$. The prevalence and impact of chronic pain with neuropathic pain symptoms in the general population. Pain Med. 2009;10:918-929. doi:10.1111/j.1526-4637.2009.00655.x

15. Langley PC. The prevalence, correlates and treatment of pain in the European Union. Curr Med Res Opin. 2011;27:463-480. doi:10.1185/03007995.2010.542136

16. Breivik H, Eisenberg E, O'Brien T, OPENMinds. The individual and societal burden of chronic pain in Europe: the case for strategic prioritisation and action to improve knowledge and availability of appropriate care. BMC Public Health. 2013;13:1229. doi:10.1186/1471-2458-13-1229

17. O'Connor AB. Neuropathic pain: quality-of-life impact, costs and cost effectiveness of therapy. Pharmacoeconomics. 2009;27:95-112. doi:10.2165/00019053-200927020-00002

18. Attal N, Lanteri-Minet M, Laurent B, Fermanian J, Bouhassira D. The specific disease burden of neuropathic pain: results of a French nationwide survey. Pain. 2011;152:2836-2843. doi:10.1016/j.pain.2011.09.014

19. Smith BH, Torrance N. Epidemiology of neuropathic pain. Pain Manag. 2011;1:87-96. doi:10.2217/pmt.10.5

20. Langley PC, Van Litsenburg C, Cappelleri JC, Carroll D. The burden associated with neuropathic pain in Western Europe. J Med Econ. 2013;16:85-95. doi:10.3111/13696998.2012.729548

21. Gaskin DJ, Richard P. The economic costs of pain in the United States. J Pain. 2012;13:715-724. doi:10.1016/j.jpain.2012.03.009

22. EuroStat. Eurostat news release. Eurostat. [Online]; March30, 2017. Cited September 27, 2019. Available from: http://ec.europa.eu/euro stat/documents/2995521/7962764/1-30032017-AP-EN.pdf.

23. World Health Organization (WHO). Cancer pain relief; 1986. https://apps.who.int/iris/handle/10665/43944. Accessed January $18,2020$.

24. Reid C, Davies A. The World Health Organization three-step analgesic ladder comes of age. Palliat Med. 2004;1:175-176. doi:10.1191/0269216304pm897ed

25. Frieden TR, Houry D. Reducing the risks of relief-the CDC opioid-prescribing guideline. $N$ Engl $J \quad$ Med. 2016;374:1501-1504. doi:10.1056/NEJMp1515917

26. Just JM, Schwerbrock F, Bleckwenn M, Schnakenberg R, Weckbecker K. Opioid use disorder in chronic non-cancer pain in Germany: a cross sectional study. BMJ Open. 2019;9:e026871. doi:10.1136/bmjopen-2018-026871

27. Kalkman GA, Kramers C, van Dongen RT, van den Brink W, Schellekens A. Trends in use and misuse of opioids in the Netherlands: a retrospective, multi-source database study. Lancet Publ Health. 2019;4:e498-e505. doi:10.1016/S2468-2667(19) 30128-8

28. International Narcotics Control Board. Narcotic Drugs. Estimated World Requirements for 2019; 2018. Statistics for 2017. Available from: https://www.drugsandalcohol.ie/30398/1/INCBNarcotics_Drugs_Technical_Publication_2018.pdf. Accessed January 9, 2020..

29. Dowell D, Haegerich TM, Chou R. CDC guideline for prescribing opioids for chronic pain - United States, 2016. MMWR Recomm Rep. 2016;65(1):1-49. doi:10.15585/mmwr.rr6501e1
30. Manchikanti L, Kaye AM, Knezevic NN, et al. Responsible, safe, and effective prescription of opioids for chronic non-cancer pain: american Society of Interventional Pain Physicians (ASIPP) guidelines. Pain Physician. 2017;20:S3-S92. doi:10.36076/ppj.2017.s92

31. O'Brien T, Christrup LL, Drewes AM, et al. European Pain Federation position paper on appropriate opioid use in chronic pain management. Eur J Pain. 2017;21:3-19. doi:10.1002/ejp.970

32. Attal N, Cruccu G, Baron R, et al. European Federation of Neurological Societies. EFNS guidelines on the pharmacological treatment of neuropathic pain: 2010 revision. Eur J Neurol. 2010;17(9):1113-e88. doi:10.1111/j.1468-1331.2010.02999.x

33. Guy GW, Stott CG. The development of Sativex ${ }^{\circledR}$ - a natural cannabis-based medicine. In: Mechoulam R editor. Cannabinoids as Therapeutics. Milestones in Drug Therapy MDT. Birkhäuser Basel;2005:231-263. doi:10.1007/3-7643-7358-X_14

34. Karst M, Wippermann S, Ahrens J. Role of cannabinoids in the treatment of pain and (painful) spasticity. Drugs. 2010;70:2409-2438. doi:10.2165/11585260-000000000-00000

35. Pertwee RG. The diverse $\mathrm{CB} 1$ and $\mathrm{CB} 2$ receptor pharmacology of three plant cannabinoids: delta9-tetrahydrocannabinol, cannabidiol and delta9-tetrahydrocannabivarin. $B r \quad J$ Pharmacol. 2008;153:199-215. doi:10.1038/sj.bjp.0707442

36. Devinsky O, Cilio MR, Cross H, et al. Cannabidiol: pharmacology and potential therapeutic role in epilepsy and other neuropsychiatric disorders. Epilepsia. 2014;55:791-802. doi:10.1111/ epi. 12631

37. McPartland JM, Duncan M, Di Marzo V, Pertwee RG. Are cannabidiol and $\Delta(9)$-tetrahydrocannabivarin negative modulators of the endocannabinoid system? A systematic review. $\mathrm{Br}$ J Pharmacol. 2015;172:737-753. doi:10.1111/bph.12944

38. Sativex Oromucosal Spray. Summary of product characteristics; April 2019. Available from: https://www.medicines.org.uk/emc/ product/602/smpc. Accessed January 18, 2020.

39. Mackie K. Cannabinoid receptors: where they are and what they do. J Neuroendocrinol. 2008;20(Suppl 1):10-14. doi:10.1111/ j.1365-2826.2008.01671.x

40. Maldonado R, Baños JE, Cabañero D. The endocannabinoid system and neuropathic pain. Pain. 2016;157(Suppl 1):S23-S32. doi:10.1097/j.pain.0000000000000428

41. Maccarrone M, Bab I, Bíró T, et al. Endocannabinoid signaling at the periphery: 50 years after THC. Trends Pharmacol Sci. 2015;36:277-296. doi:10.1016/j.tips.2015.02.008

42. Wilson RI, Nicoll RA. Endocannabinoid signaling in the brain. Science. 2002;296:678-682. doi:10.1126/science.1063545

43. Puighermanal E, Marsicano G, Busquets-Garcia A, Lutz B, Maldonado R, Ozaita A. Cannabinoid modulation of hippocampal long-term memory is mediated by mTOR signaling. Nat Neurosci. 2009;12:1152-1158. doi:10.1038/nn.2369

44. Maccarrone M, Guzmán M, Mackie K, Doherty P, Harkany T. Programming of neural cells by (endo)cannabinoids: from physiological rules to emerging therapies. Nat Rev Neurosci. 2014;15:786-801. doi:10.1038/nrn3846

45. Hoffman AF, Lupica CR. Synaptic targets of $\Delta 9$-tetrahydrocannabinol in the central nervous system. Cold Spring Harb Perspect Med. 2013;3 (8):a012237. doi:10.1101/cshperspect.a012237

46. Di Marzo V, Stella N, Zimmer A. Endocannabinoid signalling and the deteriorating brain. Nat Rev Neurosci. 2015;16:30-42. doi:10.1038/nrn3876

47. Laprairie RB, Bagher AM, Kelly ME, Denovan-Wright EM. Cannabidiol is a negative allosteric modulator of the cannabinoid CB1 receptor. Br J Pharmacol. 2015;172:4790-4805. doi:10.1111/ bph. 13250

48. Ibeas Bih $\mathrm{C}$, Chen $\mathrm{T}$, Nunn $\mathrm{AV}$, Bazelot $\mathrm{M}$, Dallas $\mathrm{M}$, Whalley BJ. Molecular targets of cannabidiol in neurological disorders. Neurotherapeutics. 2015;12:699-730. doi:10.1007/ s13311-015-0377-3 
49. Zhornitsky S, Potvin S. Cannabidiol in humans-the quest for therapeutic targets. Pharmaceuticals (Basel). 2012;5:529-552. doi:10.3390/ph5050529

50. Boswell-Casteel RC, Hays FA. Equilibrative nucleoside transporters - A review. Nucleosides Nucleotides Nucleic Acids. 2017;36:7-30. doi:10.1080/15257770.2016.1210805

51. Pérez de Vega MJ, Gómez-Monterrey I, Ferrer-Montiel A, GonzálezMuñiz R. Transient receptor potential melastatin 8 channel (TRPM8) modulation: cool entryway for treating pain and cancer. J Med Chem. 2016;59:10006-10029. doi:10.1021/acs.jmedchem.6b00305

52. Leyva-Illades D, Demorrow S. Orphan G protein receptor GPR55 as an emerging target in cancer therapy and management. Cancer Manag Res. 2013;5:147-155. doi:10.2147/CMAR.S35175

53. Garcia-Garcia AL, Newman-Tancredi A, Leonardo ED. 5-HT (1A) receptors in mood and anxiety: recent insights into autoreceptor versus heteroreceptor function. Psychopharmacology (Berl). 2014;231:623-636. doi:10.1007/s00213-013-3389-x

54. Burgos CF, Yévenes GE, Aguayo LG. Structure and pharmacologic modulation of inhibitory glycine receptors. Mol Pharmacol. 2016;9:318-325. doi:10.1124/mol.116.105726

55. Jiang L, Wang Y, Xu Y, Ma D, Wang M. The transient receptor potential ankyrin type 1 plays a critical role in cortical spreading depression. Neuroscience. 2018;382:23-34. doi:10.1016/j. neuroscience.2018.04.025

56. De Gregorio D, McLaughlin RJ, Posa L, et al. Cannabidiol modulates serotonergic transmission and reverses both allodynia and anxiety-like behavior in a model of neuropathic pain. Pain. 2019;160:136-150. doi:10.1097/j.pain.0000000000001386

57. Maccarrone M, Maldonado R, Casas M, Henze T, Centonze D. Cannabinoids therapeutic use: what is our current understanding following the introduction of THC, THC:CBD oromucosal spray and others? Expert Rev Clin Pharmacol. 2017;10:443-455. doi:10.1080/17512433.2017.1292849

58. National Academies of Sciences, Engineering, and Medicine; Health and Medicine Division; Board on Population Health and Public Health Practice; Committee on the Health Effects of Marijuana: An Evidence Review and Research Agenda. The Health Effects of Cannabis and Cannabinoids: The Current State of Evidence and Recommendations for Research. Source. Washington (DC): National Academies Press (US). The National Academies Collection: Reports funded by National Institutes of Health; January 2017.

59. Vučković S, Srebro D, Vujović KS, Vučetić Č, Prostran M. Cannabinoids and pain: new insights from old molecules. Front Pharmacol. 2018;9:1259. doi:10.3389/fphar.2018.01259

60. Potter DJ. A review of the cultivation and processing of cannabis (Cannabis sativa L.) for production of prescription medicines in the UK. Drug Test Anal. 2014;6:31-38. doi:10.1002/dta.1531

61. Perez J. Combined cannabinoid therapy via an oromucosal spray. Drugs Today (Barc). 2006;42:495-503. doi:10.1358/ dot.2006.42.8.1021517

62. Russo E, Guy GW. A tale of two cannabinoids: the therapeutic rationale for combining tetrahydrocannabinol and cannabidiol. Med Hypotheses. 2006;66(2):234-246. doi:10.1016/j.mehy.2005.08.026

63. Potter DJ, Clark P, Brown MB. Potency of delta 9-THC and other cannabinoids in cannabis in England in 2005: implications for psychoactivity and pharmacology. J Forensic Sci. 2008;53:90-94. doi:10.1111/j.1556-4029.2007.00603.x

64. Chong MS, Wolff K, Wise K, Tanton C, Winstock A, Silber E. Cannabis use in patients with multiple sclerosis. Mult Scler. 2006;12:646-651. doi:10.1177/1352458506070947

65. Stott CG, Wright S, Guy GW. Comparison of pharmacokinetic profiles of inhaled delta-9-tetrahydrocannabinol (THC) from smoked cannabis with Sativex ${ }^{\circledR}$ oromucosal spray in humans, implications for possible symptomatic treatment in multiple sclerosis. Eur $J$ Neurol. 2008;15:222-390. doi:10.1111/j.1468-1331.2008.02286.x
66. Aldington S, Harwood M, Cox B, et al. Cannabis use and risk of lung cancer: a case-control study. Eur Respir J. 2008;31:280-286. doi:10.1183/09031936.00065707

67. Epidiolex prescribing information; June 2018. Available from: https://www.accessdata.fda.gov/drugsatfda_docs/label/2018/ 210365lbl.pdf. Accessed January 18, 2020.

68. European Pharmaceutical Review. Cannabidiol-based treatment receives marketing approval from EMA; July 30, 2019. Available from: https://www.europeanpharmaceuticalreview.com/ news/95506/marijuana-based-treatment-approval-ema/. Accessed January 18, 2020.

69. Marinol prescribing information. August 2017. Available from: https://www.accessdata.fda.gov/drugsatfda_docs/label/2017/ 018651s029lbl.pdf. Accessed January 18, 2020.

70. Syndros prescribing information. July 2017. Available from: https://www.accessdata.fda.gov/drugsatfda_docs/label/2016/ 205525s000lbl.pdf. Accessed January 18, 2020.

71. Cesamet prescribing information. May 2006. Available from: https://www.accessdata.fda.gov/drugsatfda_docs/label/2006/ 018677s0111bl.pdf. Accessed January 18, 2020.

72. Häuser W, Finn DP, Kalso E, et al. European Pain Federation (EFIC) position paper on appropriate use of cannabis-based medicines and medical cannabis for chronic pain management. Eur J Pain. 2018;22:1547-1564. doi:10.1002/ejp.1297

73. Wade DT, Makela P, Robson P, House H, Bateman C. Do cannabis-based medicinal extracts have general or specific effects on symptoms in multiple sclerosis? A double-blind, randomized, placebo-controlled study on 160 patients. Mult Scler. 2004;10 (4):434-441. doi:10.1191/1352458504ms1082oa

74. Collin C, Davies P, Mutiboko IK, Ratcliffe S, Sativex Spasticity in MS Study Group. Randomized controlled trial of cannabis-based medicine in spasticity caused by multiple sclerosis. Eur J Neurol. 2007;14(3):290-296. doi:10.1111/ j.1468-1331.2006.01639.x

75. Collin C, Ehler E, Waberzinek G, et al. A double-blind, randomized, placebo-controlled, parallel-group study of Sativex, in subjects with symptoms of spasticity due to multiple sclerosis. Neurol Res. 2010;32:451-459. doi:10.1179/016164109X12590518685660

76. Novotna A, Mares J, Ratcliffe S, et al. A randomized, doubleblind, placebo-controlled, parallel-group, enriched-design study of nabiximols* (Sativex $\left({ }^{\circledR}\right)$ ), as add-on therapy, in subjects with refractory spasticity caused by multiple sclerosis. Eur J Neurol. 2011;18:1122-1131. doi:10.1111/j.1468-1331.2010.03328.x

77. Markovà J, Essner U, Akmaz B, et al. Sativex ${ }^{\circledR}$ as add-on therapy vs. further optimized first-line ANTispastics (SAVANT) in resistant multiple sclerosis spasticity: a double-blind, placebocontrolled randomised clinical trial. Int $J$ Neurosci. 2019;129:119-128. doi:10.1080/00207454.2018.1481066

78. Vermersch P. Sativex $\left({ }^{\circledR}\right)$ (tetrahydrocannabinol + cannabidiol), an endocannabinoid system modulator: basic features and main clinical data. Expert Rev Neurother. 2011;11:15-19. doi:10.1586/ ern. 11.27

79. Notcutt W, Langford R, Davies P, et al. A placebo-controlled, parallel-group, randomized withdrawal study of subjects with symptoms of spasticity due to multiple sclerosis who are receiving long-term Sativex ${ }^{\circledR}$ (nabiximols). Mult Scler. 2012;18:219-228. doi:10.1177/1352458511419700

80. Ziemssen T. Tetrahydrocannabinol:cannabidioloromucosal spray for treating symptoms of multiple sclerosis spasticity: newest evidence. Neurodegener Dis Manag. 2019;9(2s):1-2. doi: $10.2217 / \mathrm{nmt}-2018-0048$

81. Otero-Romero S, Sastre-Garriga J, Comi G, et al. Pharmacological management of spasticity in multiple sclerosis: systematic review and consensus paper. Mult Scler. 2016;22:1386-1396. doi:10.1177/1352458516643600 
82. Caraceni A, Shkodra M. Cancer pain assessment and classification. Cancers (Basel). 2019;11(4):E510. doi:10.3390/ cancers 11040510

83. Johnson JR, Burnell-Nugent M, Lossignol D, Ganae-Motan ED, Potts R, Fallon MT. Multicenter, double-blind, randomized, placebo-controlled, parallel-group study of the efficacy, safety, and tolerability of THC:CBD extract and THC extract in patients with intractable cancer-related pain. J Pain Symptom Manage. 2010;39:167-179. doi:10.1016/j.jpainsymman.2009.06.008

84. Johnson JR, Lossignol D, Burnell-Nugent M, Fallon MT. An open-label extension study to investigate the long-term safety and tolerability of $\mathrm{THC} / \mathrm{CBD}$ oromucosal spray and oromucosal THC spray in patients with terminal cancer-related pain refractory to strong opioid analgesics. $J$ Pain Symptom Manage. 2013;46:207-218. doi:10.1016/j.jpainsymman.2012.07.014

85. Portenoy RK, Ganae-Motan ED, Allende S, et al. Nabiximols for opioid-treated cancer patients with poorly-controlled chronic pain: a randomized, placebo-controlled, graded-dose trial. J Pain. 2012;13:438-449. doi:10.1016/j.jpain.2012.01.003

86. Lichtman AH, Lux EA, McQuade R, et al. Results of a double-blind, randomized, placebo-controlled study of nabiximols oromucosal spray as an adjunctive therapy in advanced cancer patients with chronic uncontrolled pain. J Pain Symptom Manage. 2018;55:179-188.e1. doi:10.1016/j.jpainsymman.2017.09.001

87. Rog DJ, Nurmikko TJ, Friede T, Young CA. Randomized, controlled trial of cannabis-based medicine in central pain in multiple sclerosis. Neurology. 2005;65:812-819. doi:10.1212/01. wnl.0000176753.45410.8b

88. Rog DJ, Nurmikko TJ, Young CA. Oromucosal delta9-tetrahydrocannabinol/cannabidiol for neuropathic pain associated with multiple sclerosis: an uncontrolled, open-label, 2-year extension trial. Clin Ther. 2007;29:2068-2079. doi:10.1016/j.clinthera.2007.09.013

89. Langford RM, Mares J, Novotna A, et al. A double-blind, randomized, placebo-controlled, parallel-group study of THC/CBD oromucosal spray in combination with the existing treatment regimen, in the relief of central neuropathic pain in patients with multiple sclerosis. J Neurol. 2013;260:984-997. doi:10.1007/s00415-012-6739-4

90. ClinicalTrials.gov. A study to evaluate the effects of cannabis based medicine in patients with pain of neurological origin. Available from: https://clinicaltrials.gov/ct $2 / \mathrm{show} /$ NCT01606176. Accessed January 18, 2020.

91. Russo M, Naro A, Leo A, et al. Evaluating Sativex ${ }^{\circledR}$ in neuropathic pain management: a clinical and neurophysiological assessment in multiple sclerosis. Pain Med. 2016;17:1145-1154. doi: $10.1093 / \mathrm{pm} / \mathrm{pnv} 080$

92. ClinicalTrials.gov. A study of cannabis based medicine extracts and placebo in patients with pain due to spinal cord injury. Available from: https:/clinicaltrials.gov/ct2/show/results/ NCT01606202. Accessed January 18, 2020.

93. Berman JS, Symonds C, Birch R. Efficacy of two cannabis based medicinal extracts for relief of central neuropathic pain from brachial plexus avulsion: results of a randomised controlled trial. Pain. 2004;112:299-306. doi:10.1016/j.pain.2004.09.013
94. Nurmikko TJ, Serpell MG, Hoggart B, Toomey PJ, Morlion BJ, Haines D. Sativex successfully treats neuropathic pain characterised by allodynia: a randomised, double-blind, placebo-controlled clinical trial. Pain. 2007;133:210-220. doi:10.1016/j.pain.2007.08.028

95. Serpell M, Ratcliffe S, Hovorka J, et al. A double-blind, randomized, placebo-controlled, parallel group study of THC/CBD spray in peripheral neuropathic pain treatment. Eur J Pain. 2014;18:999-1012. doi:10.1002/j.1532-2149.2013.00445.x

96. ClinicalTrials.gov. A double blind, randomized, placebo controlled, parallel group study of Sativex in the treatment of subjects with pain due to diabetic neuropathy. Available from: https:/clinicaltrials.gov/ ct2/show/NCT00710424. Accessed January 18, 2020.

97. Hoggart B, Ratcliffe S, Ehler E, et al. A multicentre, open-label, follow-on study to assess the long-term maintenance of effect, tolerance and safety of THC/CBD oromucosal spray in the management of neuropathic pain. $J$ Neurol. 2015;262:27-40. doi: 10.1007/s00415-014-7502-9

98. Lynch ME, Cesar-Rittenberg P, Hohmann AG. A double-blind, placebo-controlled, crossover pilot trial with extension using an oral mucosal cannabinoid extract for treatment of chemotherapy-induced neuropathic pain. J Pain Symptom Manage. 2014;47:166-173. doi:10.1016/j.jpainsymman.2013.02.018

99. Ito S, Kobayashi D, Murasawa A, et al. An analysis of the neuropathic pain components in rheumatoid arthritis patients. Intern Med. 2018;57:479-485. doi:10.2169/internalmedicine.9235-17

100. Blake DR, Robson P, Ho M, Jubb RW, McCabe CS. Preliminary assessment of the efficacy, tolerability and safety of a cannabis-based medicine (Sativex) in the treatment of pain caused by rheumatoid arthritis. Rheumatology (Oxford). 2006;45:50-52. doi:10.1093/rheumatology/kei183

101. Ueberall MA, Essner U, Mueller-Schwefe GH. Effectiveness and tolerability of THC:CBD oromucosal spray as add-on measure in patients with severe chronic pain: analysis of 12-week open-label real-world data provided by the German Pain e-Registry. J Pain Res. 2019;12:1577-1604. doi:10.2147/JPR.S192174

102. Freynhagen R, Baron R, Gockel U, Tölle TR. painDETECT: a new screening questionnaire to identify neuropathic components in patients with back pain. Curr Med Res Opin. 2006;22:1911-1920. doi:10.1185/030079906X132488

103. Freynhagen R, Tölle TR, Gockel U, Baron R. The painDETECT projectfar more than a screening tool on neuropathic pain. Curr Med Res Opin. 2016;32:1033-1057. doi:10.1185/03007995.2016.1157460

104. Flachenecker P, Henze T, Zettl UK. Nabiximols (THC/CBD oromucosal spray, Sativex $\left.{ }^{\circledR}\right)$ in clinical practice-results of a multicenter, non-interventional study (MOVE 2) in patients with multiple sclerosis spasticity. Eur Neurol. 2014;71(5-6):271-279. doi:10.1159/000357427

105. Patti F, Messina S, Solaro C, et al. Efficacy and safety of cannabinoid oromucosal spray for multiple sclerosis spasticity. J Neurol Neurosurg Psychiatry. 2016;87:944-951. doi:10.1136/jnnp-2015-312591
Journal of Pain Research

\section{Publish your work in this journal}

The Journal of Pain Research is an international, peer reviewed, open access, online journal that welcomes laboratory and clinical findings in the fields of pain research and the prevention and management of pain. Original research, reviews, symposium reports, hypothesis formation and commentaries are all considered for publication. The manuscript management system is completely online and includes a very quick and fair peer-review system, which is all easy to use. Visit http:// www.dovepress.com/testimonials.php to read real quotes from published authors. 